\title{
Micro reflectance imaging spectroscopy for pigment identification in painting cross sections
}

Marc Vermeulen ${ }^{1}$, Katherine Eremin ${ }^{2}$, Georgina Rayner ${ }^{2}$, Kate Smith $^{2}$, Timothy Cavanaugh ${ }^{3}$, Arthur McClelland ${ }^{4}$ and Marc Walton ${ }^{5}$

${ }^{1}$ NUACCESS/Northwestern University, United States, ${ }^{2}$ Harvard Art Museums, United States, ${ }^{3}$ Harvard University, Center for Nanoscale Systems, United States, ${ }^{4}$ Harvard University, Center for Nanoscale Systems, Cambridge, Massachusetts, United States, ${ }^{5}$ Northwestern University, United States

Elemental and electronic techniques have been used for decades in the field of cultural heritage in order to investigate artists' palette and technique. Because non-invasive and non-destructive macroscopic approaches are often preferred for the investigation of works of art, X-ray fluorescence scanning, and reflectance imaging spectroscopy imaging are often go-to techniques for objects-based and objectsinspired scientific investigations in the field of Heritage Science [1-5]. However, these techniques do not easily provide information regarding the layer build up, the complexity of pigment mixtures used, and allow for the investigation of single pigment particles. To this end, microsamples are usually extracted from the work of art and prepared as cross sections, thus allowing the investigator to have access to the various layers constituting the work of art. Such cross sections are usually investigated using elemental and vibrational spectroscopies such as SEM-EDX and Raman spectroscopy, the latter often requiring at least two lasers to cover the range of possible pigments used. However, these techniques are often associated with beam-induced damages in the form of cracks, burned areas, etc. (Fig. 1) that may cause changes in the molecular structure of the pigments under study or may result in possible longer-term degradation processes [6,7]. Such damages to the precious art samples are, however, usually not associated with reflectance spectroscopy, which prompted the development of a reflectance imaging microscope ( $\mu$-RIS) by Northwestern's Center for Scientific Studies in the Arts [8].

This paper introduces the application of $\mu$-RIS to the study of complex paint cross sections obtained on historical paintings. The 430-1000 $\mathrm{nm}$ and 10 angles acquisition (with 36-degree rotation) approach allows to create a spectral stack of diffuse only scattered light, thus eliminating all possible artifacts associated with cross section preparation. The data cube produced is then processed using a recent laboratorydeveloped freely available reflectance spectroscopy data treatment tool to create pigment distribution maps and associated reflectance curves that can be used to identify the pigments employed [2]. We will present here both the main components of the spectral microscope and its application to complex multilayered cross sections sampled on several paintings, including Paul Gauguin's painting PoèmesBarbares(Fig. 2; object number: 1951.49). The results of this non-destructive approach will be compared with elemental and molecular distribution maps obtained using SEM-EDX and Raman spectroscopy, alongside the associated beam damage on the cross sections. 

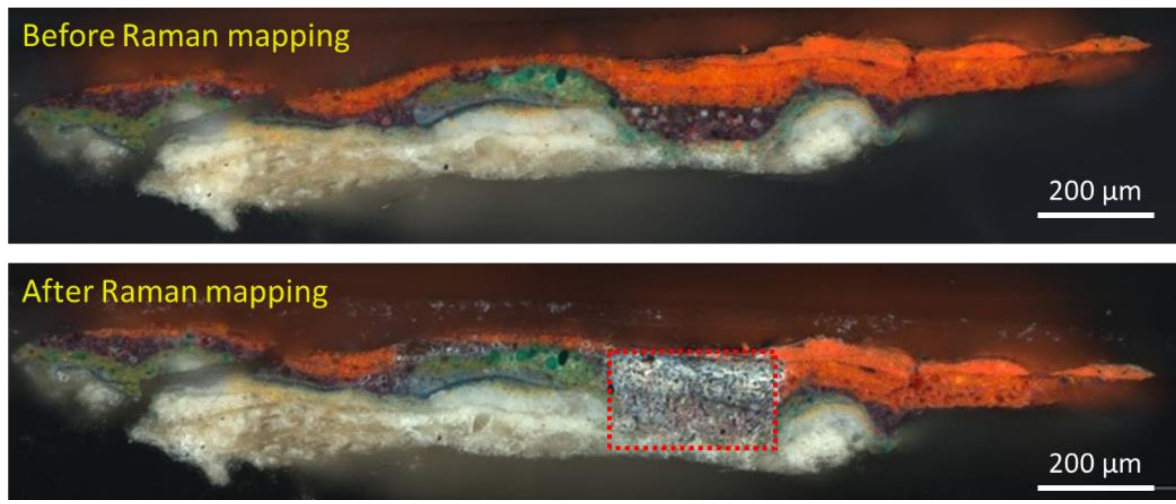

Figure 1. Cross section taken from Gauguin's PoèmesBarbares imaged before (top) and after (bottom) Raman mapping. The dotted red rectangle indicates the laser beam damage associated with the Raman mapping.

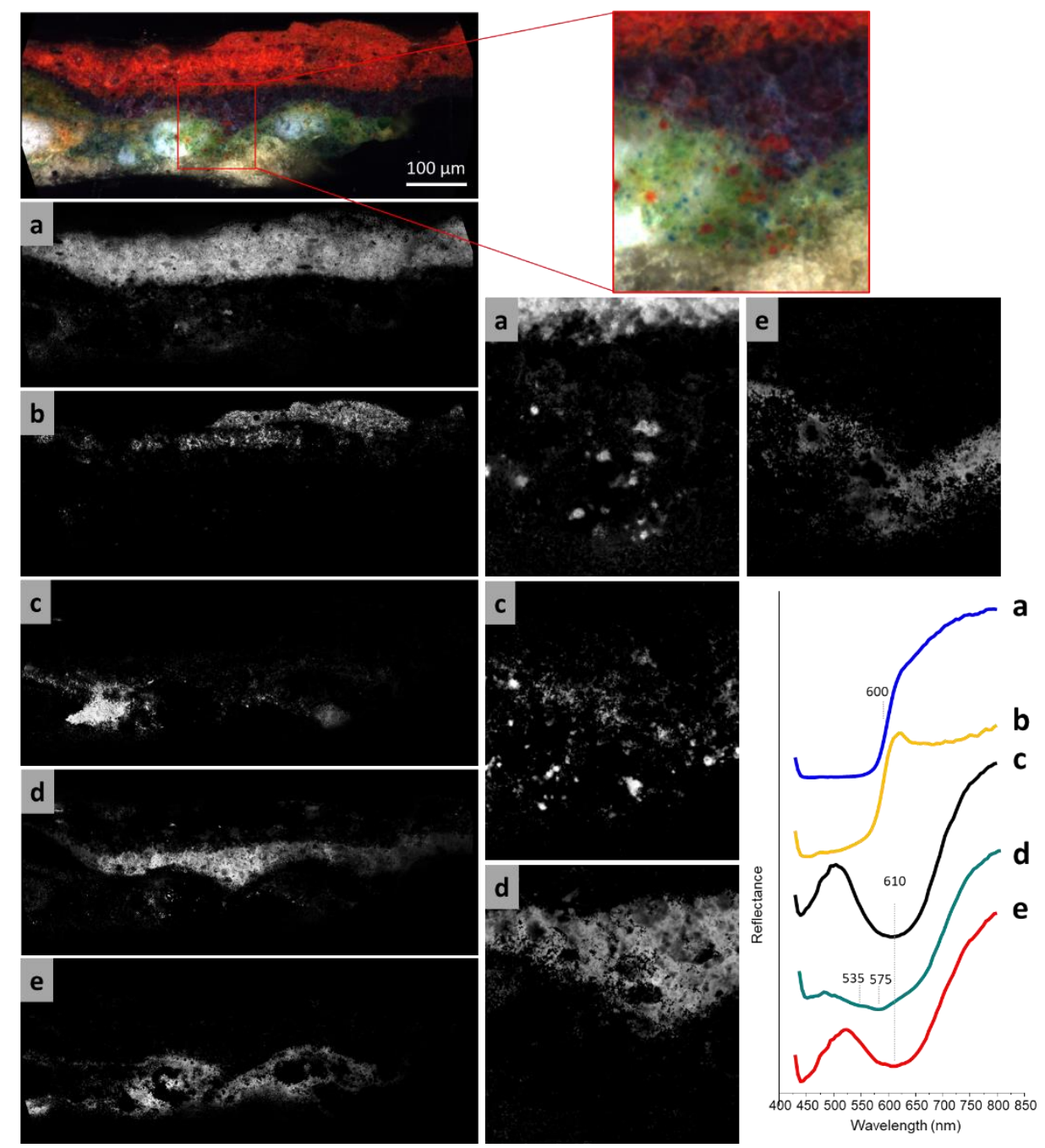

Figure 2. RGB image (left: full field of view; right: detail) of the paint cross section taken from Gauguin's PoèmesBarbares and (a-e) pigment distribution maps and associated reflectance curves obtained using NUACCESS $\mu$-RIS microscope. Pigment identification: (a,b) vermilion; (c) ultramarine blue; (d) organic red/ultramarine blue purple; and (e) ultramarine blue-containing green. 


\section{References}

[1] M.L. Clarke, F. Gabrieli, K.L. Rowberg, A. Hare, J. Ueda, B. McCarthy, J.K. Delaney, Imaging spectroscopies to characterize a 13th century Japanese handscroll, The Miraculous Interventions of JizōBosatsu, Heritage Science 9(1) (2021) 20.

[2] M. Vermeulen, K. Smith, K. Eremin, G. Rayner, M. Walton, Application of Uniform Manifold Approximation and Projection (UMAP) in spectral imaging of artworks, Spectrochimica Acta Part A: Molecular and Biomolecular Spectroscopy 252 (2021) 119547.

[3] J.K. Delaney, D.M. Conover, K.A. Dooley, L. Glinsman, K. Janssens, M. Loew, Integrated X-ray fluorescence and diffuse visible-to-near-infrared reflectance scanner for standoff elemental and molecular spectroscopic imaging of paints and works on paper, Heritage Science 6(1) (2018) 31.

[4] J.K. Delaney, K.A. Dooley, A. van Loon, A. Vandivere, Mapping the pigment distribution of Vermeer's Girl with a Pearl Earring, Heritage Science 8(1) (2020) 4.

[5] E. Pouyet, K. Brummel, S. Webster-Cook, J. Delaney, C. Dejoie, G. Pastorelli, M. Walton, New insights into Pablo Picasso's La Miséreuseaccroupie (Barcelona, 1902) using X-ray fluorescence imaging and reflectance spectroscopies combined with micro-analyses of samples, SN Applied Sciences 2(8) (2020) 1408.

[6] A. Ul-Hamid, A Beginners' Guide to Scanning Electron Microscopy, 1 ed., Springer International Publishing2018.

[7] A. Burnstock, C. Jones, Scanning electron microscopy techniques for imaging materials from paintings, in: D.C. Creagh, D.A. Bradley (Eds.), Radiation in Art and Archeometry, Elsevier Science B.V., Amsterdam, 2000, pp. 202-231.

[8] L. Oakley, S. Zaleski, B. Males, O. Cossairt, M. Walton, Improved spectral imaging microscopy for cultural heritage through oblique illumination, Heritage Science 8(1) (2020) 27. 